\title{
The ethnic prevalence of hypertension in a diabetic clinic
}

\author{
P. J. PACY \\ M.B., M.R.C.P. \\ M. BEEVERS \\ S.R.N.
}

\author{
P. M. DODSON \\ M.B., M.R.C.P. \\ R. F. FLETCHER \\ M.D., Ph.D., F.R.C.P.
}

\author{
K. G. TAYLOR \\ M.D., M.R.C.P. \\ Department of Diabetes and Endocrinology, Dudley Road Hospital, Birmingham B18 $7 Q H$
}

\begin{abstract}
Summary
Using the WHO criteria of hypertension, we have demonstrated that $40 \%$ of randomly selected diabetic clinic attenders under the age of 65 were hypertensive.

Black diabetics had a significantly greater prevalence $(P<0.001)$ of hypertension than either white or Asian diabetics. Hypertension was commoner in black and white females compared with males $(P<0.001)$; in Asians this difference was not statistically significant.

Systolic hypertension was the most common form in all ethnic groups. Only $38.7 \%$ of diabetics receiving antihypertensive therapy had normal blood pressure readings.

Blood pressure measurement should therefore be routinely performed in all diabetic patients under the age of 65 , particularly in females of all ethnic groups and in black males.
\end{abstract}

KEY WORDS: hypertension, diabetes, blacks, whites, Asians.

\section{Introduction}

The possible association of hypertension with diabetes mellitus has been the subject of research since the early 1920s. Much of the early work on this subject was reviewed by John (1932). He concluded his paper by writing 'the consensus of opinion of various authors is that blood pressure is higher in diabetics than in non-diabetics of the same age'.

This association was challenged by Freedman, Moulton and Spencer (1958) who found that there was a significantly increased prevalence of hypertension only in diabetics over the age of 70 years.

Pell and D'Alonzo (1967) reported that in their working population, hypertension was $54 \%$ more frequent in diabetics of both sexes than in age-sex matched controls and that this was independent of obesity. They were also able to show that this difference in prevalence could be observed in the prediabetic state. The Framingham study (Garcia et al., 1974) has shown that mean systolic pressures are higher in diabetics than in age-sex matched controls with this being greater in females. Jarrett et al. (1978) in the large Bedford population study found that mean systolic blood pressures were significantly higher in men and women in borderline and established diabetics while in the male civil servants at Whitehall there was a significant positive correlation between both systolic and diastolic blood pressures and the blood glucose $2 \mathrm{hr}$ after a $50 \mathrm{~g}$ glucose load. However, the blood pressure in established diabetics was no different from that of normoglycaemic controls.

Christlieb et al. (1981) from the Joslin Clinic, Boston, reported an increased prevalence of hypertension in insulin dependent diabetics at all ages over 24 years and Barrett-Connor et al. (1981) found a positive association in an elderly community (between 50-79 years). This association was strongest in those with the highest levels of fasting glucose and duration of diabetes. This relationship although diminished remained after correcting for obesity and age.

From large multivariate studies from Philadelphia (Dunn et al., 1970), Israel (Sive et al., 1971) and Chicago (Stamler et al., 1975), an independent association between glucose intolerance and hypertension has also been observed among blacks but these findings tended to be less consistent than seen in the white population. 
Despite over 60 years of research into the prevalence of hypertension in diabetes mellitus, there remains conflicting evidence which may have arisen due to a number of methodological differences which include the definition of hypertension, how the diastolic pressure is measured and the effect of obesity on blood pressure measurement.

We have therefore studied the prevalence of hypertension in patients attending a large diabetic clinic with emphasis on eliminating many of the problems that have arisen in some of the previous papers.

\section{Methods}

We have taken the current WHO criteria of hypertension (1979) which is that of a systolic pressure $\geqslant 160 \mathrm{mmHg}$ and/or a diastolic pressure $\geqslant 95 \mathrm{mmHg}$ using the 5th Korotkoff phase.

We have also included any patient currently receiving antihypertensive therapy regardless of their blood pressure reading.

Patients under 65 attending the Diabetic Clinic were chosen by a research nurse who recorded the blood pressure with the patient in the supine position after a 5 to $10 \mathrm{~min}$ rest using a random zero sphygmomanometer.

A standard width sphygmomanometer cuff (14 cm) was used if the mid-arm circumference was less than $33 \mathrm{cms}$. If this measurement was greater than this, a large $(19 \mathrm{~cm})$ width cuff was used to negate the false elevation of blood pressure produced by a standard cuff. All the patients met the criteria of the National Diabetes Data Group (1979) for the diagnosis of diabetes mellitus.
The chi-squared and unpaired Student's $t$-test we used to determine the degree of significance between the groups.

\section{Results}

Overall, 507 diabetic patients under the age of were screened and of these $203(40 \%)$ were hyperte sive. The ethnic breakdown revealed that blacks at $48.9 \%$ had significantly greater prevalence $(P<0.00 \%$ than either whites at $37.5 \%$ or Asians at $35.4 \%$.

The prevalence of hypertension according to sex is shown in Fig. 1. Females at $48.9 \%$ had a significant greater prevalence $(P<0.001)$ of hypertension thatg males at $32.9 \%$. This increased prevalence in female was observed in the whites $(46.5 \% v .30 .1 \% ; P<0.00 \mathrm{~b}$ and in blacks $(58.6 \%$ v. $39.1 \% ; P<0.001)$. Asiag females had a greater prevalence than their maks counterparts $(41.2 \%$ v. $32.3 \%)$ but this failed to reach statistical significance.

Table 1 shows the age and percentage ideal bods weights of the patients screened. The hypertensives were significantly older than the normotensives but only in whites of both sexes and blacks overall werf the hypertensives significantly more obese than the normotensive diabetic.

The analysis of the various forms of hypertens $\overrightarrow{0}$ both overall and in each ethnic group, is show ion Table 2. Table 3 shows the response of those receiving antihypertensive therapy. Of importance the finding that of all the diabetics on treatment onl $38.7 \%$ had normal blood pressure levels with similap results in the three ethnic groups.

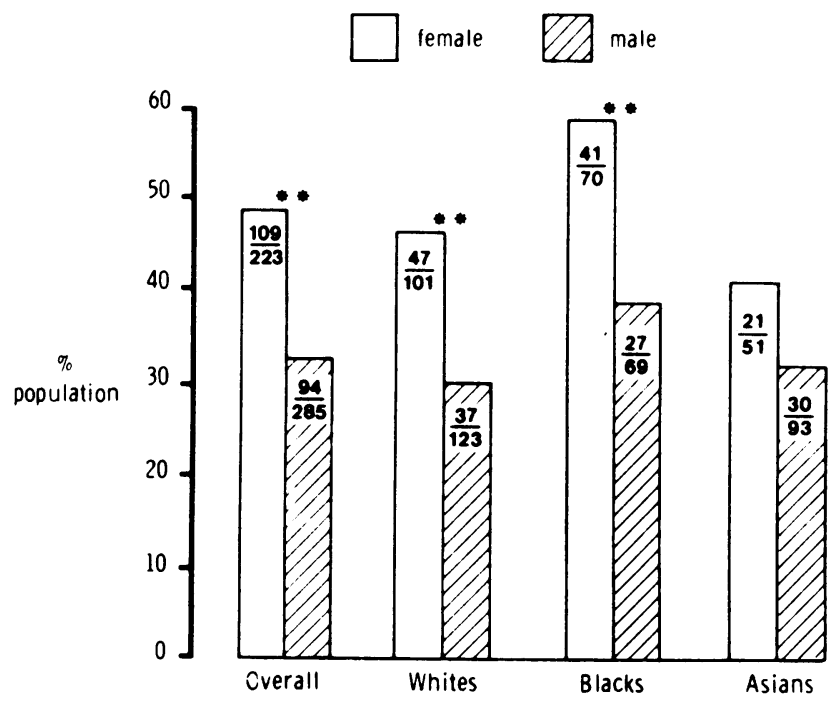

Fig. 1. Prevalence of hypertension in male and female diabetics $\left({ }^{* *} P<0.001\right.$, females $v$. males). 
TABLE 1. Clinical details of patients studied with blood pressure status, sex and ethnic origin and percent ideal body weight (mean \pm s.e.m.)

\begin{tabular}{|c|c|c|c|c|c|c|}
\hline \multirow[b]{2}{*}{ Ethnic group } & \multicolumn{3}{|c|}{ Age } & \multicolumn{3}{|c|}{$\%$ ideal body weight } \\
\hline & Normotensive & Hypertensive & $P$ & Normotensive & Hypertensive & $P$ \\
\hline \multicolumn{7}{|l|}{ White } \\
\hline $\begin{array}{l}\text { Male } \\
\text { Female }\end{array}$ & $\begin{array}{l}45.02 \pm 1.25 \\
42.02 \pm 2.06\end{array}$ & $\begin{array}{l}43.39 \pm 1.32 \\
55.45 \pm 1.02\end{array}$ & $t$ & $\begin{array}{l}116.09 \pm 1.92 \\
125.00 \pm 3.74\end{array}$ & $\begin{array}{l}130.21 \pm 3.64 \\
137.36 \pm 3.87\end{array}$ & $\dagger$ \\
\hline \multicolumn{7}{|l|}{ Black } \\
\hline $\begin{array}{l}\text { Male } \\
\text { Female }\end{array}$ & $\begin{array}{l}48.57 \pm 1.64 \\
51.55 \pm 1.46\end{array}$ & $\begin{array}{l}55 \cdot 28 \pm 0.95 \\
54 \cdot 10 \pm 0 \cdot 83\end{array}$ & $\begin{array}{l}\dagger \\
\dagger\end{array}$ & $\begin{array}{l}116 \cdot 66 \pm 2 \cdot 26 \\
138 \cdot 19 \pm 3 \cdot 62\end{array}$ & $\begin{array}{l}122 \cdot 88 \pm 2 \cdot 96 \\
138 \cdot 00 \pm 2 \cdot 98\end{array}$ & \\
\hline \multicolumn{7}{|l|}{ Asian } \\
\hline $\begin{array}{l}\text { Male } \\
\text { Female }\end{array}$ & $\begin{array}{l}46 \cdot 38 \pm 1 \cdot 24 \\
44 \cdot 70 \pm 1 \cdot 86\end{array}$ & $\begin{array}{l}50 \cdot 57 \pm 1.58 \\
52.86 \pm 1.41\end{array}$ & * & $\begin{array}{l}116.26 \pm 1.75 \\
130.64 \pm 3.65\end{array}$ & $\begin{array}{l}117 \cdot 41 \pm 2.37 \\
134.60 \pm 4.02\end{array}$ & \\
\hline
\end{tabular}

${ }^{*} P<0.05 ; \uparrow P<0.001$ for comparison of hypertensives and normotensives.

TABLE 2. Analysis of the hypertension in both males and females in each ethnic group

\begin{tabular}{lcccc}
\hline Ethnic group & $\begin{array}{c}\% \text { isolated } \\
\text { systolic } \\
\text { hypertension }\end{array}$ & $\begin{array}{c}\% \text { isolated } \\
\text { diastolic } \\
\text { hypertension }\end{array}$ & \% combined & $\begin{array}{c}\text { \% normotensive } \\
\text { on treatment for } \\
\text { hypertension }\end{array}$ \\
\hline White & & & & \\
$\quad$ Male & 48.6 & $5 \cdot 4$ & 32.4 & 13.5 \\
Female & 59.6 & $2 \cdot 1$ & $19 \cdot 1$ & $19 \cdot 2$ \\
Black & & & & \\
$\quad$ Male & 33.3 & $11 \cdot 1$ & 29.6 & 25.9 \\
Female & 48.8 & 2.4 & 34.1 & 14.6 \\
Asian & & & & \\
$\quad$ Male. & 37.9 & 10.4 & 30.0 & 20.7 \\
Female & 52.4 & 0 & 28.6 & 19.0 \\
\hline
\end{tabular}

TABLE 3. Response to hypotensive treatment in the ethnic groups studied

\begin{tabular}{lc}
\hline Ethnic group & $\begin{array}{c}\% \text { of all cases receiving } \\
\text { hypotensive drugs who were } \\
\text { normotensive at time of survey }\end{array}$ \\
\hline Whites & 38.9 \\
Blacks & 32.4 \\
Asians & 50.0 \\
\hline
\end{tabular}

\section{Discussion}

The most important finding of this study is that in a district general hospital diabetic clinic, $40 \%$ of the diabetics under the age of 65 were hypertensive. We have confirmed the findings of other authors in demonstrating that blacks had a significantly greater prevalence than whites or Asians as do females and that isolated systolic hypertension was the most common form (Epstein et al., 1965; Garcia et al., 1974).

The aetiology of hypertension in the majority of diabetics is not clear. A number of theories have been proposed among which are that the osmotic effect of hyperglycaemia results in chronic expansion of the circulating blood volume (Christlieb et al., 1975). De Châtel et al. (1977) have demonstrated that some patients have an increased total body sodium while Weidmann et al. (1979) showed that diuretics can restore body sodium and normalize the blood pressure. De Fronzo, Goldberg and Aguo (1975) have implicated insulin itself in the pathogenesis of hypertension as it probably acts on the proximal convoluted tubules to increase the reabsorption of sodium; only small increases in plasma insulin (30-40 $\mathrm{mu} /$ litre) are required for this effect.

Diabetics are more prone to atherosclerosis than non-diabetics which may result in a loss of elasticity and hence compliance in the major blood vessels and which may explain the increased prevalence of systolic hypertension. Nephropathy is also more prevalent in diabetics and may be a contributory factor.

Lastly, there is the effect of obesity on the prevalence of hypertension. This relationship has long been recognized (Fletcher, 1953; Kannel et al., 1967) and may be the reason for the apparent increase in prevalence as many diabetics are obese. 
Ragan and Bordley (1941) showed that if a normal width sphygmomanometer cuff was used to measure the blood pressure of patients with fat arms, there was a false elevation in the pressure recorded when compared to direct arterial pressure measurement. A correction factor was initially determined by Pickering, Roberts and Sowry (1954) and more recently by Maxwell et al. (1982) to minimize this effect. However, Chiang, Perlman and Epstein (1967) in a review on obesity and hypertension have concluded that 'correcting blood pressure by arm circumference will obscure the important influence of body weight on blood pressure in epidemiological studies'. Our study is in agreement with that of Demanet et al. (1976) who has shown that the association remains even after correcting for arm circumference.

We conclude that there is a high prevalence of hypertension in diabetic patients who may benefit from treatment and that this prevalence cannot be solely explained by an association with obesity. The highest prevalence was seen in black female diabetics.

\section{Acknowledgments}

P. Pacy is a Wellcome Research Fellow. We are grateful to Mrs B. Singh for typing this manuscript.

\section{References}

Barrett-Connor, E., Criqui, M.H., Klauber, M.R. \& HoldBROOK, M. (1981) Diabetes and hypertension in a community of older adults. American Journal of Epidemiology, 113, 276.

Chiang, B.N., Perlman, L.V. \& Epstein, F.H. (1969) Overweight and hypertension. A review. Circulation, 39, 403.

Christlieb, A.R., Assal, J-P., Katsilambros, N., Williams, G.H., KoZAK, G.P. \& SUZUKI, T. (1975) Plasma renin activity and blood volume in uncontrolled diabetes: ketoacidosis, a state of secondary aldosteronism. Diabetes, 24, 190.

Christlieb, A.R., Warran, J.H., Krolewski, A.S., Busick, E.J., GANDA, O.M., ASMAL, A.C., SOELDNER, J.S. \& BRADLEY, R.F. (1981) Hypertension: the major risk factor in juvenile-onset insulin dependent diabetics. Diabetes, 30 (Suppl. 2), 90.

DeChâtel, R., Weidmann, P., Flammer, J., Ziegler, W.H., BeretTA-PicColi, E., VetTer, W. \& ReUbi, F.C. (1977) Sodium, renin, aldosterone, catecholamines and blood pressure in diabetes mellitus. Kidney International, 12, 412.

DE Fronzo, R.S., GoldberG, M. \& AGNo, Z. (1976) The effect of glucose and insulin on renal electrolyte transport. Journal of Clinical Investigation, 58, 83.

Demanet, J.C., Rorive, G., Sanil, K., Van Cauwenberge, H. \& SMETS, P. (1976) Effect of weight on prevalence of hypertension and its interaction with the arm circumference: Belgian Hyperten- sion Committee epidemiological study. Clinical Science ్ㅐㅇㅔ Molecular Medicine, 51, 6655.

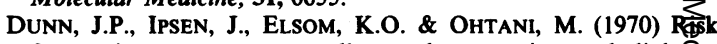
factors in coronary artery disease, hypertension and diabefes. American Journal of the Medical Sciences, 259, 309.

Epstein, F.H., Ostrander, L.B., Johnson, B.C., Payne, M.W., HAYNER, N.S., KELleR, J.B. \& FranCIS, T. (1965) Epidemiol\$gical studies of cardiovascular disease in a total community- tecumseh, Michigan. Annals of Internal Medicine, 62, 1170.

FLETCHER, A.P. (1953) The effect of weight reduction upon fhe blood pressure of obese hypertensive women. Quarterly Journat of Medicine, 91, 331.

Freedman, P., Moulton, R. \& SPENCER, A.G. (1958) Hypertension and diabetes mellitus. Quarterly Journal of Medicine, 27, 293.

Garcia, M.J., McNamara, P.M., Gordon, T. \& KanNel, $B$, (1974) Morbidity and mortality in diabetics in the Framingham population. Diabetes, 23, 105.

JARRETT, R.J., KEEN, H., MCCARTNEY, M., FULlER, J.H., HAN TON, P.J.S., REID, D.D. \& RosE, G. (1978) Glucose tolerance-Aifd blood pressure in two population samples; their relationshff to diabetes mellitus and hypertension. International JournaP of Epidemiology, 7, 15.

JOHN, H.J. (1932) Hypertension and diabetes. Annals of Interhal Medicine, 5, 1462.

KANNEL, W.B., BRAND, N., SKINNER, J.J., DAWBER, T.R. \& MC NAMARA, P.M. (1967) Relationship of adiposity to blood pressure and development of hypertension. Framingham Study. Annatsof Internal Medicine, 67, 48.

MAXWELl, M.H., WAKS, A.V., Schroth, P.C., KARAM, M. ${ }_{\text {\& }}$ DORNFIELD, L.P. (1982) Error in blood pressure measurement give to incorrect cuff size in obese patients. Lancet, ii, 33.

National Diabetes Data Group (1979) Classification and dêfgnosis of diabetes mellitus and other categories of glugegse intolerance. Diabetes, 28, 1039.

PELL, S. \& D'Alonzo, C.A. (1967) Some aspects of hyperten\&्gुogin diabetes mellitus. Journal of the American Medical Asso 202, 104.

Pickering, G.W., Roberts, J.A.F. \& SOWRY, G.S.C. (9)95) Aetiology of essential hypertension-effect of correcting for firm circumference on the growth rate of arterial pressure with age. Clinical Science, 13, 267.

RAGAN, C. \& BORDLEY, J. III (1941) The accuracy of clinffal measurements of arterial blood pressure. Bulletin of the Jahn Hopkins Hospital, 69, 504.

Sive, P.H., MEDalie, J.H., KAHN, H.A., Neufeld, H.N. \& Riss (1971) Distribution and multiple regression analysis of blgod pressure in 10,000 Israeli men. American Journal of Epidemiology, 93, 317.

Stamler, J., RHomberg, P., Schoenberger, J.A., Shekelle, R. $\overline{\text { B. }}$., DYer, A., SheKelle, S., STAMLer, R.\& Wannamaker, J. (19ळ) Multivariate analysis of the relationship of six variables to blo od pressure: findings from Chicago surveys 1965-71. Journabof Chronic Diseases, 28, 499.

Weidmann, P., Beretta-Piccoli, C., Kensch, G., Gluck, $\frac{7}{2}$., Hujagic, M., GrimM, M., Meier, A. \& Ziegler, W/H. (19q9) Sodium-volume factor, cardio-vascular reactivity and hypotensive mechanism of diuretic therapy in mild hypertension associated with diabetes mellitus. American Journal of Medicine, 67, 779?

WHO (1979) Report of a WHO Expert Committee of Hypertension. WHO Technical Report Series, Geneva. 